\title{
The best time for extubation-daylight at the end of the tunnel?
}

(c) The Author(s), under exclusive licence to Springer Nature America, Inc. 2021

\author{
Journal of Perinatology (2021) 41:2381-2382; https://doi.org/10.1038/ \\ s41372-021-01199-z
}

In this issue of the Journal of Perinatology, Guy et al. attempt to evaluate whether extubation success is less likely to occur when extubation is performed during night shifts [1]. This is an age-old question among neonatologists, which might not be unique to the issue of extubation. Is there a difference in outcomes for procedures performed at night as opposed to during daylight hours? Several studies have evaluated different short-term outcomes, with the most notable being that of Lee et al. who found that there was a higher early mortality rate among infants born $<32$ weeks' gestation when they were admitted at night compared to during the day [2]. However, elective extubation timing is likely to be one of the most controversial issues among neonatologists.

Why do we stress so much over what seems to be a simple decision? Infants who are extubated "too early" run the risk of many complications. Namely, the biggest concern is the need for reintubation. Reintubation comes with procedural risks such as laryngeal or airway trauma, pneumothorax, laryngospasm, and emesis with aspiration. In infants who are extubated too "early", the majority of reintubations are likely secondary to atelectasis and subsequent ventilation/perfusion mismatch. At the time of reintubation, these infants are often much sicker than when they were extubated, leading to a more urgent or emergent reintubation. Umoren et al. recently published that high-stress intubations are more likely to result in adverse events [3]. In the pediatric intensive care unit, such adverse events are also more likely to occur during intubations that occur at night and the weekends [4].

However, a delay in extubation also has adverse complications on a growing neonate. There is the risk of ventilator-associated pneumonia, movement of an endotracheal tube leading to rightmainstem intubation, subglottic stenosis and additional ventilatorinduced lung damage. Unplanned extubation may lead to cardiovascular collapse and has also been linked with an increase in length of stay and hospital costs [5, 6]. Although waiting to extubate "until the morning" may not seem like much, deferring extubation from the afternoon/evening handoff of care until the next day leads to up to $15 \mathrm{~h}$ of additional, unnecessary ventilation. In an infant who is getting a ventilator rate of 30 breaths per minute, this is an additional 27,000 breaths of forced volume that is not needed and is an "invisible harm" to premature lungs. Thus, if we decide that a child is a good candidate for successful extubation, why not do it then regardless of the time of the day? Obviously, in the very many units in the developing world and probably also in the multiple ones in the developed world where night staffing (doctors, nurses, and respiratory therapists) is much lighter than day staffing, the reason for concern is obvious.

The best way to ascertain whether night-time extubation is as safe as day-time extubation would of course be a randomized controlled trial (RCT) evaluating the difference. As Guy et al. note, an RCT of extubation timing would be unethical. If such an RCT was constructed, the infant would need to be deemed acceptable to extubate and then randomized to either extubating at that time (likely during the day during rounds) or delaying the extubation until the night shift. Neonatologists would not have equipoise, nor should they, in delaying extubation in an infant who is physiologically ready for the reasons noted above. This clearly would not satisfy the moral concepts of beneficence and nonmaleficence that physicians and researchers need to follow. Although not as ideal as an RCT, analysis of data from large networks or collaborations would provide additional insights into knowledge translatable into practice.

For that reason, Guy et al. did not randomize their patients, and their study became a non-interventional, unblinded, observational study. And indeed, as they feared, patients extubated at night and those extubated during dayshifts were strikingly different at baseline: babies extubated at night were larger and less sick than those extubated during the daytime, which may have given them an inherent advantage for extubation success. Thus, Guy et al had to do some "adjustments" to take into account this great source of bias. What did they do? They used a smart way that has been developed to compare "apples and oranges" by using entropy balancing analyses. This type of analysis is a novel, elegant way to adjust for differences by rearranging the data in a balanced manner, i.e., by matching each "apple" to the "orange" that resembles it the most (here, in our case, in terms of gestational age, small for gestational age status, 5-min Apgar score, peak supplemental oxygen during the first $24 \mathrm{~h}$, supplemental oxygen at extubation, and postnatal age at extubation). Yet, we are still comparing "apples with oranges", since, from the start, day and night populations were very different. Thus, in our opinion, we cannot reach certainty for the answer to this research question in a non-RCT trial which puts us in a quandary-it's unethical to perform an RCT and at the same time retrospective evaluation of different populations will not definitively answer the question.

We however applaud the authors for attempting to evaluate such a controversial topic in our field and our NICUs, even if the question: "Is it as safe to extubate at night as it is during the day?" is not answered by this analysis. This paper is the first step in working towards that answer, but we agree with the authors that more work needs to be done. Until then, clinical neonatologists should continue to weigh the pros and cons of extubation at a particular time, taking into account the patient's condition and just as importantly, the local systems in place to allow safe extubation and potential reintubation of each patient.

\section{DISCLOSURES}

JRS and FM are associate editors for the Journal of Perinatology. 
Jonathan R. Swanson ${ }^{1 \otimes}{ }^{\otimes}$ and Francis Mimouni ${ }^{2,3}$ ${ }^{1}$ Department of Pediatrics, University of Virginia Children's Hospital, Charlottesville, VA, USA. ${ }^{2}$ Department of Neonatology, Shaare Zedek Medical Center, Jerusalem, Israel. ${ }^{3}$ Sackler School of Medicine, Tel Aviv, Israel. ${ }^{\bowtie}$ email: jswanson@virginia.edu

\section{REFERENCES}

1. Guy BG, Dye ME, Richards L, Guthrie SO, Hatch LD. Association of time of day and extubation success in very low birthweight infants: a multicenter cohort study. J Perinatol 2021. [Online ahead of print]

2. Lee SK, Lee DSC, Andrews WL, Baboolal R, Pendray M, Stewart S, the Canadian Neonatal Network. Higher mortality rates among inborn infants admitted to neonatal intensive care units at night. J Pediatr. 2003;143:592-7.

3. Umoren RA, Sawyer TL, Ades A, DeMeo S, Foglia EE, Glass K, et al. Team stress and adverse events during neonatal tracheal intubations: a report from NEAR4NEOS. Am J Perinatol. 2020;37:1417-24.

4. Rehder KJ, Giuliano JS, Napolitano N, Turner DA, Nuthall G, Nadkarni VM, et al. Increased occurrence of tracheal intubation-associated events during nights and weekends in the PICU. Crit Care Med. 2015;43:2668-74.
5. Klugman D, Berger JT, Spaeder MC, Wright A, Pastor W, Stockwell DC. Acute harm: unplanned extubations and cardiopulmonary resuscitation in children and neonates. Intensive Care Med. 2013;39:1333-34.

6. Roddy DJ, Spaeder MC, Pastor W, Stockwell DC, Klugman D. Unplanned extubations in children: impact on hospital cost and length of stay. Pediatr Crit Care Med. 2015;16:572-5.

\section{AUTHOR CONTRIBUTIONS}

JRS and FM both conceptualized the product and wrote and edited the manuscript and approved the final draft.

\section{ADDITIONAL INFORMATION}

Correspondence and requests for materials should be addressed to J.R.S.

Reprints and permission information is available at http://www.nature.com/ reprints

Publisher's note Springer Nature remains neutral with regard to jurisdictional claims in published maps and institutional affiliations. 